A Saciopoética, an:

quando grupas-pesquisadores se tornam filósofos coletivas.

Jacques Gauthier

Unijorge - Centro Universitário Jorge Amado

Salvador - Bahia - Brasil

jacques.jupaty@terra.com.br

Resumo: A sociopoética como prática de pesquisa transforma os objetos de investigação em grupos-pesquisadores que apresentam as principais características de um filósofo coletivo: conforme Deleuze e Guattari, eles elaboram problemas, eles criam confetos (misturas de conceitos e afetos) como rizomas e ritornelos, e eles geram personagens conceituais. O autor o mostra a partir de pesquisas realizadas em escola comunitária e aldeia indígena. 


\section{O que é sociopoética?}

A sociopoética (ver a revista eletrônica www.entrelugares.ufc.br e a obra coordenada por Santos, Gauthier, Figueiredo e Petit, 2005) é uma abordagem de pesquisa em ciências do ser humano e da sociedade, enfermagem e educação, com possibilidades de aplicação no ensino e na aprendizagem, que segue cinco orientações básicas:

1) A instituição do dispositivo do grupo-pesquisador, no qual cada participante da pesquisa está ativo em todas as etapas dessa pesquisa (produção dos dados, leituras analíticas e transversais desses dados, socialização...), e pode interferir no devir da pesquisa. Isso garante a chamada de formas variadas de racionalidade e a possibilidade de que outras fontes de conhecimento, não racionais e sim emocionais, intuitiva, sensíveis, imaginativas e motrizes, entrem em jogo;

2) A valorização das culturas dominadas e de resistência é uma orientação que, diretamente, aponta para outras maneiras de interpretar o mundo, não eurodescendentes e que foram marginalizadas pela colonização e pelo capitalismo. Portanto, estão colocados em interação dialógica com as teorias em vigor no mundo acadêmico modos diferentes de interpretar os dados de pesquisa (até, produzindo esses dados nas próprias formas dessas culturas, onde o corpo possui um papel essencial);

3) Os sociopoetas pretendem pensar, conhecer, pesquisar, aprender com o corpo inteiro, ao equilibrarem as potências da razão pelas da emoção, das sensações, da intuição, da gestualidade, da imaginação... Muitos saberes não se expressam com palavras, por terem sido recalcados nos nossos músculos e nervos por opressões diversas ou por pertencerem à ordem do silêncio, do sagrado ou da dança;

4) Ao privilegiarem formas artísticas de produção dos dados, os sociopoetas colocam em jogo capacidades criadoras que mobilizam o corpo inteiro e revelam fontes não conscientes de conhecimento - fontes que muitos atores e atrizes da pesquisa ignoravam possuir antes do decorrer da pesquisa; logo, eles não teriam podido utilizar essas fontes em formas mais convencionais de pesquisa tais como entrevistas, as quais são muito mais relevantes após o 
estudo coletivo das produções artísticas, no sentido de precisar, aprofundar ou ampliar os problemas construídos;

5) Enfim, os sociopoetas insistem na responsabilidade ética, política, noética e espiritual do grupo-pesquisador, em todo momento do processo de pesquisa, que não é propriedade dos pesquisadores “profissionais”, que não é somente voltado para o mundo acadêmico, e sim deve interferir com as necessidades e desejos dos grupos que acolhem as pesquisas. Essa última orientação favorece a desconstrução dos corpos assim como a emergência de desejos e devires imprevisíveis.

\section{Antes de prosseguir: pequeno ABC ortográfico e conceitual}

Confeto: o grupo-pesquisador cria três tipos de produção intelectual, os problemas - no sentido filosófico dessa palavra (um problema é o resultado do processo de problematização, a partir de uma dificuldade no pensamento oriunda do absurdo, de uma contradição, de um paradoxo ou da heterogeneidade das fontes de pensamento), os personagens conceituais e os confetos. Não pretendemos criar conceitos, preferimos deixar essa tarefa aos filósofos profissionais. E sim, assumir nossa originalidade de sempre mexer, ao mesmo tempo, com o racional e o afeto, já que mobilizamos o corpo inteiro como fonte de conhecimento. Assim criamos a palavra "confeto" para nomear essas misturas íntimas de conceito e afeto que o grupo-pesquisador vai criando. Em regra geral, os confetos aparecem somente no momento em que os facilitadores estudam o pensamento do grupo-pesquisador como se fosse obra de um só cérebro, pois é preciso realizar oposições e ligações entre dados para elaborar um confeto original.

Contra-análise: é o momento em que o grupo-pesquisador estuda criticamente as hipóteses dos facilitadores sobre seu pensamento (sobre o inconsciente do seu pensamento!), hipóteses pelas quais os facilitadores propõem problemas e confetos. É um momento dialógico, onde não se trata de saber quem tem razão no caso de divergência entre copesquisadores e facilitadores, e sim de ampliar as visões, introduzindo mais diferenciação, mais heterogeneidade, numa palavra só: mais complexidade. Na contra-análise podem surgir novos problemas e novos confetos. 
Copesquisador, copesquisadora: membro do grupo-pesquisador que não é facilitador.

Facilitador, facilitadora: um membro de destaque do grupo-pesquisador! $\mathrm{O}$ ou a pesquisador(a) profissional, acadêmico(a) ou oficial, como quiser. Seu papel é importante, pois aprendeu a discrição, ou seja, não interferir na produção do pensamento dos demais membros do grupo, ou melhor (pois mesmo o silêncio é uma forma de interação!), interferir de maneira mínima e metódica. Como? Ao saber trazer as condições para que se institua um coletivo responsável e autogerido, onde as relações de poder, saber e desejo sejam as mais visíveis e compartilhadas possíveis; ao saber implantar técnicas artísticas de produção de dados; ao saber estudar os dados produzidos, procurando o inconsciente do grupo-pesquisador; ao saber organizar a análise crítica, no seio do grupo, tanto desses dados como do estudo elaborado por ele próprio. Ao saber desbloquear situações de fuga frente à exigência do conhecimento... De fato, é bom que participem dois ou duas facilitadores/as, pois não é simples, ao mesmo tempo, cuidar do bom desenvolvimento da pesquisa e observar o que acontece no grupo-pesquisador.

Grupo-pesquisador: o hífen é importante, porque não se trata de um grupo que pesquisa, mas de um ser coletivo, que se institui no início da pesquisa como grupo-sujeito do seu devir. Gostamos de dizer que ele age na pesquisa como se fosse um único pensador, percorrido por caminhos diversos, às vezes contrários, que se encontram, tecem juntos ou divergem...

Tema-gerador (pode ser escrito com ou sem hífen): o tema da pesquisa, ou seja, uma noção simples ou composta - a ser elaborada coletivamente. Às vezes, a pergunta de pesquisa deve ser um pouco diferente do tema-gerador, quando, para tomar o exemplo de uma pesquisa desenvolvida num quilombo do Ceará, o grupo hóspede encontra muitos preconceitos que dificultam a expressão direta de si. Neste caso, investigar diretamente “O que é ser negro" fracassou, pois os copesquisadores sofriam tanto da estigmatização racial que para eles, o "negro" somente podia ser o outro. Se a pergunta não fosse transformada, as pessoas nunca teriam falado de si, ainda menos da sua experiência do racismo e da estigmatização. O temagerador é negociado. Ele pode ser proposto pelos facilitadores (como problema de uma pesquisa acadêmica) ou pela instituição hóspede da pesquisa, como na pesquisa-ação. 


\section{Como acontece uma pesquisa sociopoética?}

Após negociação com a instituição hóspede da pesquisa dos tempos e espaços colocados à disposição para a investigação (experimentamos que uma boa média é a formação de grupospesquisadores de 8 a 16 membros, com aproximadamente 8 sessões de 2 horas), e escolha do tema-gerador da pesquisa, a pesquisa propriamente dita começa com um relaxamento, que tem por objetivo a livre circulação das energias e a flexibilização do pensamento, a fim de favorecer a emergência de dados não conscientes (inconscientes, numa visão pós-freudiana ou despertos, numa visão pós-budista). Neste estado de relaxamento, os copesquisadores, membros do grupopesquisador, deixam fluir imagens em resposta às perguntas do/a facilitador/a. No grupo, uma primeira expressão individual dos dados assim produzidos acontece, com rápido estudo coletivo do conjunto desses dados. Em seguida, os facilitadores, em casa, estudam sistematicamente esses dados, como se fossem a produção de um único cérebro coletivo, complexo, com contradições, diferenciações etc. Os mestrandos e doutorandos que, desde já uns 15 anos desenvolveram pesquisas sociopoéticas, geralmente, tiveram dificuldades neste momento da pesquisa. Há de desenvolver, aqui, além da escuta sensível (BARBIER, 1993) sempre ativa, um olhar de estruturalista para ver a forma do pensamento do grupo, a partir dos dados produzidos por cada um. Isso não é fácil. Deste estudo, num primeiro tempo analítico, em seguida mais transversal (relacionando, como num pensamento "oriental” ou holístico, o que a análise separou), nascem hipóteses em resposta à pergunta: Quais são os problemas e os confetos criados, inconscientemente, pelo grupo? Esses problemas e confetos são trazidos ao grupopesquisador para contra-análise coletiva (divergências entre os facilitadores e demais membros do grupo-pesquisador podem acontecer e são consideradas como produtivas). Entrevistas individuais permitem precisar a diferença do aporte de cada um e sua contribuição na constelação cognitiva e afetiva coletivamente criada. Segue um momento de socialização, acadêmica e no meio social hóspede da pesquisa.

\section{Algumas técnicas de pesquisa inspiradas nas artes}


É importante lembrar que em toda pesquisa, sociopoética ou não, os dados produzidos dependem da técnica utilizada. Por isso utilizamos pelo menos duas técnicas diferentes. Aqui vou expor quatro técnicas entre as dezenas já utilizadas, uma inspirada no teatro, outras na filosofia, na literatura, e nas artes plásticas (performances). Cada facilitador/a pode criar técnicas novas. Aconteceu, até, conforme Batista, 2003, que Jovita, xamã de uma aldeia indígena pataxó da Bahia e copesquisadora numa pesquisa cujo tema-gerador era “Como brincam os indígenas”, propôs à facilitadora Geovanda Batista a instituição de uma dinâmica de produção de dados através do ritual sagrado Awê, dança que relaciona os participantes à Mãe-terra e aos ancestrais (Encantados).

- A primeira é a primeira técnica que desenvolvi como técnica sociopoética: a técnica do teatroimagem, diretamente inspirada do Teatro do Oprimido de Augusto Boal (1988). Nosso objetivo é diferente do de Augusto Boal, que propõe a cada participante apresentar uma imagem congelada, emocional e esteticamente forte (e não realista) de uma opressão que ele sofreu, sem comentar nem explicá-la; num segundo tempo, cada participante comenta essa imagem, trazendo seu olhar sobre a opressão sofrida - o que, para o autor da imagem (a pessoa que sofreu a opressão apresentada), é um “outro olhar” abrindo, às vezes, perspectivas novas e transformadoras para sua vida. O autor fala por último. No Teatro-imagem, o grupo pode intervir, ao modificar a imagem numa perspectiva libertadora. O objetivo dos sociopoetas é a pesquisa, logo, adaptamos a técnica teatral. Mantivemos a idéia de que um, dois, três, quatro corpos congelados apresentassem uma alegoria oriunda de uma imagem mental (o acolhimento de imagens não óbvias e talvez mais autênticas, ausentes no campo ordinário da consciência, mas presentes no subconsciente ou numa consciência desperta, é favorecido pelo relaxamento). No caso, a imagem é diretamente relacionada ao tema investigado. Cada participante dá sua leitura dessa imagem e o ou a autor(a) fala por último, não como representante da verdade daquilo que se devia ver, e sim, como um dos portadores do significado, entre os demais participantes. Diferentemente da técnica criada por Augusto Boal, como não se trata diretamente de opressão, parece melhor que o/a copesquisador(a) autor(a) da imagem não participe da imagem, ficando com o papel de encenador da mesma. A depender da preferência dos facilitadores, pode-se pedir para o grupo fazer evoluir a imagem (logo, o pensamento), ou não. Às vezes criamos teatro-imagens coletivas, em pequenos grupos de três ou quatro 
copesquisadores, mas sempre com a diretriz de que, no processo de criação coletiva, não se percam as diferenças entre as percepções de cada um dos autores e que se anote como ocorre o processo de negociação para criação da imagem coletiva. Com efeito, a sociopoética enfatiza as diferenças e nunca busca nem os pensamentos mais freqüentes nem o consenso, ainda menos a homogeneização. Pelo contrário, trabalha no sentido de acabar com a dominação das idéias gerais e majoritárias.

- A segunda técnica é uma técnica utilizada por mim em muitas pesquisas, pois favorece diretamente a criação coletiva de confetos, a técnica dos lugares geomíticos. Ela nasceu de maneira muito estranha, na confluência entre a intervenção de Michel Serres realizada no seminário sobre A Identidade coordenado por Claude Lévi-Strauss (1983) que se referia a um velho jogo europeu chamado de Jeu de l'Oie (“Jogo do Ganso”) com seus lugares remarcáveis como o Poço, a Ponte, o Labirinto, o Hotel, a Prisão etc., e minha experiência da paisagem kanak na Nova Caledonia (Ilha do Pacífico-Sul ainda colonizada pela França), onde Caminhos, Montes, Rios, Grutas etc. podem ser sagrados: tem de pedir autorização ao clã cujos ancestrais possuem esses lugares, para freqüentar alguns, e outros são proibidos, tabus. Mortos, espíritos, seres encantados ou assustadores freqüentem os lugares da Natureza. Na intervenção de Michel Serres, os lugares do Jeu de l'Oie são como elementos que compõem a identidade “cultural”, sempre pensada como sistema dinâmico, não definido uma vez por toda, de relações complexas: estamos muito distantes das crenças culturalistas ou políticas que dão uma identidade simples, global e única a tal ou qual grupo social! Na sociopoética, cada facilitador(a) pode idealizar os lugares geomíticos que lhe parecem pertinentes. Minha experiência e as contribuições de outros/as sociopoetas me conduziu a selecionar a Ponte, o Vento, a Falha, o Rio, o Labirinto, a Galáxia, o Caminho, a Fronteira e o Poço. Praticamente, quando os copesquisadores estiverem em estado de relaxamento, um facilitador faz uma pergunta do tipo, se o tema-gerador fosse uma Ponte, como seria essa Ponte, imagine os detalhes... Deixando uns 20 segundos para que imagens precisas surjam em cada um(a), ele faz a mesma pergunta com outro "lugar": se fosse um Vento, como seria esse vento, imagine os detalhes... Diferentemente da técnica do teatroimagem onde o/a autor(a) fala por último, após as leituras propostas pelos parceiros, aqui, cada um explicita primeiro as visualizações que teve. É bom, até, prever um material para que todos possam escrever ou desenhar suas visualizações imediatamente após a dinâmica de produção de 
dados, pois são fugazes. Em seguida, geralmente numa sessão ulterior, os autores relacionam suas visões ao tema, e só depois fica aberto um espaço para a fala coletiva; nesse caso, mais para uma discussão geral sobre o conjunto das produções que para comentários sobre cada criação. As visualizações são mais imediatas que os teatro-imagens, já que nestes geralmente participa o raciocínio individual a partir da imagem recebida no relaxamento. Logo, parece melhor que, na técnica dos lugares geomíticos, o grupo não intervinha muito sobre as visualizações de cada um, meio íntimas, sensíveis, como aquelas flores chamadas de sensitivas que se fecham desde que se toca. Talvez pareça tudo isso, para quem me lê, meio abstrato, mas é só praticar... para intuir o que é melhor em termos de criação coletiva de conhecimentos e em termos de significados que enfatizem a produção de diferenças.

- A terceira técnica é a técnica da história a continuar. Em relação ao tema-gerador da pesquisa, os facilitadores contam uma história, na qual é fácil para os participantes se identificarem com tal ou qual personagem. A astúcia é de chegar a um ponto onde existe um conflito intenso, e as personagens devem fazer escolhas claras (obviamente não sugeridas, nunca induzidas e sim deixadas abertas à criatividade dos copesquisadores). Por escrito ou oralmente, eles inventam continuações individuais da história. A justificação e discussão das várias escolhas é riquíssima e dá apoio para elaborar a complexidade do problema de pesquisa. Pois cabe aos facilitadores entenderem como se configura a paisagem mental do grupo, ou seja, em que pontes, poços, labirintos, caminhos múltiplos, encruzilhadas, subterrâneos, becos sem saída, válvulas etc. passa o pensamento do grupo-pesquisador considerado como um só cérebro coletivo. Várias continuações da mesma história desenham bifurcações, oposições firmes e pequenas diferenças... que depois podem se juntar de novo, mas de maneira original, cruzar outros caminhos mais ou menos imprevistos etc.

- A quarta técnica é a técnica dos sentidos. É simples: os facilitadores escolhem elementos - da natureza ou não - que podem ser bons suportes sensíveis para o pensamento. Existem pelo menos duas variantes: de olhos vendados, cada copesquisador experimenta com o sentido corporal envolvido na pesquisa, por exemplo, 5 elementos escolhidos pelos facilitadores e depois, comenta o que sentiu e como isso ecoou com o tema-gerador da pesquisa; em outra versão, sempre de olhos vendados e após relaxamento, cada copesquisador escolhe alguns elementos (por exemplo, 3 entre 12 possíveis) que caracterizam, segundo ele, sua relação com o 
tema-gerador da pesquisa. Nos dois casos, os elementos estão apresentados a cada copesquisador pelos facilitadores: são cheiros se o sentido envolvido na pesquisa é o olfato, são texturas, se pesquisamos com o tato etc. A escolha, pelos facilitadores, de elementos a serem apresentados aos copesquisadores que não induzam o pensamento é importante. É imprescindível dizer claramente ao grupo que não se trata de reconhecer o elemento (não é adivinhar o que é), e sim associar livremente com o tema. Freqüentemente, ao justificarem suas escolhas, eles contam pedaços de sua história de vida! É bom, pois fortalece o aspecto individual e singular da pesquisa. Mas é igualmente importante que o grupo-pesquisador se conscientize do seu pensamento coletivo, ao despertar sua atenção sobre os significados variados dados ao mesmo elemento por copesquisadores diferentes, e comece assim a perceber a forma, a estrutura do pensamento de grupo. Por exemplo, o gosto do sal relacionado ao tema-gerador da aprendizagem pode, para um, gerar associações ligadas ao prazer de intensificar a vida graças ao saber e para outra, lembrar simplesmente a comida da vó, sendo a família um elemento importante no processo de aprendizagem.

\section{A sociopoética, um filosofar novo: problematizando}

Concordo com os criadores da Esquizo-análise, Gilles Deleuze e Félix Guattari que, no seu livro O que é Filosofia (1992), definem a filosofia como elaboração de problemas e criação de conceitos. Nossa ambição, nas pesquisas sociopoéticas, é bem de elaborar, coletiva e cooperativamente, problemas que, antes, não estavam presentes na consciência do grupopesquisador. Os problemas tomam a forma de contradições ou paradoxos (ver Deleuze, 1969) em todos os casos, de conflitos no pensamento. O exemplo que gosto de lembrar, onde vimos a pesquisa sociopoética favorecer a elaboração de um problema relevante, é a pesquisa financiada pelo CNPq que realizei na Escola Comunitária Luiza Mahin no Bairro Uruguai da cidade baixa de Salvador (GAUTHIER e GAUTHIER, 2001). O grupo-pesquisador era constituído de educadoras da escola. Em sessão de contra-análise apareceu de repente o problema bem escondido do status da escrita para as copesquisadoras, na sua prática cotidiana. Escrita problemática porque ao mesmo tempo, constitui-se num espaço privilegiado reservado ao mais íntimo e mais gostoso da pessoa e, ao mesmo tempo, é uma prática difícil para educadoras de 
meio popular, de cultura mais oral. Não era um problema da vida a ser resolvido, como por exemplo, para aprender a escrever bem, mas era um problema filosófico mesmo, que obrigava a pensar diferentemente e a questionar certas práticas acostumadas. Principalmente, a justificativa político-pedagógica freqüentemente avançada da necessidade de alfabetizar as crianças para elas se tornarem adultos que saibam defender seus direitos, que conheçam as leis e tenham capacidade de liderança nas lutas populares. Atrás dessa justificativa programática, tinha um desejo escondido das próprias educadoras em relação à escrita.

Quem era questionada agora era a própria pessoa da educadora frente à escrita e não a criança. Esse “retorno do recalcado”, como diria Freud, favoreceu uma construção problemática coletiva complexa com 4 pólos, a escrita, a oralidade, a arte e a ciência (escrevemos um artigo coletivo com autoria de todos os membros do grupo-pesquisador, publicado em Panorama Acadêmico 4/5, Revista do Campus de Jacobina - Bahia - da UNEB, Universidade do Estado da Bahia ver Gauthier, 2000). No decorrer da pesquisa sociopoética, o projeto da escola comunitária estava em processo de encontrar novas motivações e novas definições, no vai e vem entre esses 4 pólos. Num primeiro tempo, a arte era mais a “arte de fazer” (tão importante como prática pedagógica) que a arte no sentido de pintura, música, dança etc.; foi somente num momento posterior da pesquisa, principalmente com o grupo-pesquisador de crianças que valorizou muito a aprendizagem das artes (desenho, capoeira, dança etc.), que a arte tomou esta última definição. Conseqüentemente - isso foi um efeito inesperado da pesquisa - a pedagogia da escola evoluiu em direção à arte-educação. O grupo-pesquisador instaurou a problemática da tradução entre oralidade e escrita e entre arte e ciências, no mesmo tempo que tentou pensar o lugar das novas tecnologias.

$\mathrm{O}$ fato de que os grupos-pesquisadores sociopoetas trabalham com o corpo inteiro e com a imaginação abre muitas possibilidades de problematização original do tema-gerador da pesquisa. No referido exemplo dos grupos-pesquisadores da Escola Comunitária Luiza Mahin, o temagerador foi, para os três coletivos, de educadoras, de pais e mães e de crianças, a investigação do que era “uma aprendizagem gostosa e que faz sentido”. Em regra geral, há de confiar nas extraordinárias capacidades da imaginação humana, sobretudo quando as pessoas compartilham uma experiência gostosa e desestabilizadora de pesquisa! Com certeza existem aí possibilidades para a elaboração de problemas relacionando esferas da vida geralmente isoladas, que filósofos 
profissionais nem pensariam juntar.

\section{A sociopoética, um filosofar novo: confetualizando}

Deleuze e Guattari vêem na filosofia uma atividade de criação de conceitos, caracterizados pela sua intensidade e sua capacidade a "fazer rizoma”. Se quisermos dar uma imagem adequada do que é um conceito filosófico, há de pensar na figura musical chamada de "ritornelo” (Deleuze, 2002, acrescentará o conceito como Galope). E, por que não, o Passo, como nas procissões (procissões do conceito?) e o Trote, como em vários tipos de maratonas, institucionais ou não. E o Pulo? Formas de conceitos e confetos, formas de tempo, ruídos do tempo. Sempre ligados a elementos incorporais, desterritorializantes, pois pensar não é se tornar preso de um território, nem mesmo de uma terra, mesmo que nativa ou ancestral. Em todos os casos há imanência do conceito, nunca transcendência. Deleuze e Guattari (1992, p. 25-26) tomam um exemplo instrutivo: O conceito de um pássaro não se encontra no seu gênero ou sua espécie, mas na composição de suas posturas, de suas cores e de seus cantos; algo indiscernível que é menos uma sinestesia que uma sineidesia. Um conceito é uma heterogênese, ou seja, uma ordinação de seus componentes por zonas de vizinhança. Ele é ordinal, é uma intensão presente em todos os traços que o compõem. Ao não cessar de percorrê-los, seguindo uma ordem sem distância, o conceito está em estado de sobrevôo em relação a seus componentes. Ele está imediatamente co-presente, sem distância alguma, a todos seus componentes ou variações, ele passa e repassa por eles: é um ritornelo, um opus que tem seu número.

Ele ressoa sem cessar em si mesmo e com outros conceitos (nesse exemplo, ele ressoa com os conceitos de território, de luz, de chamada, cada um desses conceitos tendo suas próprias variações).

Diferentemente da ciência que descobre funções (ou seja, relações sistemáticas entre variáveis independentes), assim como da arte que cria "perceptos” e afetos novos. Para nós sociopoetas, a filosofia também lida com os afetos, já que os grupos-pesquisadores criam confetos - misturas, no pensamento, de conceitos e afetos, da mesma maneira que, segundo Deleuze e Guattari, a arte 
cria misturas de afetos e perceptos. Um percepto pode ser, por exemplo, o preto na pintura de Manet, o amarelo dos girassóis de Van Gogh, ou ainda, as curvas vegetais de Oscar Niemeyer. Deleuze e Guattari chamam simplesmente o percepto de bloco de sensações. Por exemplo, o que sinto e que, desafiando a análise, vai mudando meu ritmo cardíaco a cada vez que me aproximo da catedral de Brasília.

Um afeto não é um sentimento, e sim uma potencialização do corpo, uma energização diferente do ser. Como, por exemplo, o que muda em nós quando ouvimos uma sucessão de acordos de João Gilberto. O afeto é zona de indeterminação, indiscernibilidade entre os reinos, minerais, animais, pessoas, coisas e forças da natureza. É um devir não-humano do homem, como em Clarice Lispector (1998, p. 179) na última página da Paixão segundo G.H.:

Mas agora, eu era muito menos que humana - e só realizaria meu destino especificamente humano se me entregasse, como estava me entregando, ao que já não era eu, ao que já é inumano. E entregando-me com a confiança de pertencer ao desconhecido. Pois só posso rezar ao que não conheço. E só posso amar a evidência desconhecida das coisas, e só posso me agregar ao que desconheço. Só esta é que é uma entrega real. E tal entrega é o único ultrapassamento que não me exclui.

O confeto, como misto de conceito e afeto, faz em outro plano o que realiza a arte, a qual mistura percepto e afeto. Parece que Deleuze e Guattari estão próximos de nós, pois concebem a filosofia em eco à arte. É só ler como eles definem o percepto (1992, p. 172): "Tornar sensíveis as forças insensíveis que povoam o mundo, e que nos afetam, fazem com que nós devenhamos.” Particularmente, o tempo. E, na página 173: “Há plena complementaridade, abraço das forças como perceptos e dos devires como afetos” [...] “Às forças cósmicas ou cosmogenéticas correspondem devires-animais, vegetais, moleculares: até que o corpo desvaneça-se” (etc.). Na sociopoética, com a criação de confetos queremos tornar inteligíveis essas forças que povoam o mundo e nos afetam; seguindo a metáfora, podemos falar, na sociopoética, dos confetos como abraço das forças como conceitos e dos devires como afetos.

Isso nos toca particularmente, pois nas culturas colonizadas, africanas e indígenas, o pensamento é uma forma de energia, inexistem abstrações que não sejam, ao mesmo tempo, expressões de energias da natureza-espírito. Por exemplo, no candomblé, da mesma maneira que existem tipos 
de pessoas que expressam a energia Xangô, e outras pessoas, a energia Oyá ou a energia Oxalá, existem pensamentos com “cor” de tal ou tal orixá (ver Gleason, 1999; Gauthier, dez/1999; Oliveira, 2003, 2007).

Encontramos em Deleuze e Guattari, 1992, uma rápida referência ao que poderia ser uma composição de afeto e conceito para eles, quando, na pág. 165, eles falam dos afetos, desconhecidos ou mal conhecidos, que um romancista como Chrétien de Troyes cria: “Os estados crepusculares dos cavalheiros (em relação a um conceito eventual de cavalaria)”. Nós, nos grupos-pesquisadores, percebemos estados solares ou crepusculares, estelares ou luares, nublados ou outros... no momento em que criamos confetos. Outro afeto sugestivo segundo nossos filósofos, “a fraternidade entre dois lobos” em Emily Brontë, afeto que não pode ser confundido com o amor e que nós sociopoetas já encontramos em vários grupos-pesquisadores. Ou ainda, os blocos musicais na música de Bartók ou Debussy.

Os confetos sociopoéticos ecoam com os conceitos-ritornelos segundo Deleuze e Guattari, já que freqüentemente têm forma de rizomas, como veremos a seguir.

$\mathrm{Na}$ referida pesquisa, desenvolvida junto à Escola Comunitária Luiza Mahin, o grupopesquisador de crianças entre 7 e 11 anos criou confetos interessantes. Para ele, a aprendizagem que tem sentido e que é prazerosa vai firmando e unificando o Eu, território cuja necessidade é fortemente expressa pelos alunos - os quais são muito, e até, demais desterritorializados e fluentes. O Eu vai se fortalecendo através de experimentações onde estão em jogo os seguintes confetos: prazer-arte-violência em si próprio (a arte permite a elaboração dessa violência) e cuidar-brincar-professora-livro (o ensino/aprendizagem é uma forma do cuidar, como nas sociedades indígenas e africanas, mas onde intervém o livro). Esses confetos são os rizomas que melhor caracterizam a noção de "aprendizagem gostosa”.

Uma leitura dos dados da pesquisa feita por um pai-de-santo a partir da cosmovisão do candomblé traz outros aspectos, que vou brevemente apresentar. Os confetos da "aprendizagem gostosa” são como bonecas russas que se encaixariam umas em outras da seguinte forma:

- O primeiro confeto rizomatiza a partir de quatro atratores: os territórios adultos (escola e família); a caça ao saber (desterritorializante); a sedução e o prazer; a violência interna.

- Esse último atrator desdobra-se num segundo confeto, também rizomatizando a partir de quatro atratores: a luta no saber; o poder de comunicação e tradução; a arte; a alteração 
espiritual (justiça e paz).

Através de misturas e matizes comunicam os confetos de "violência interna" e "aprendizagem gostosa”.

- O atrator “alteração espiritual”, por sua vez, desdobra-se num terceiro confeto, rizomatizando a partir de quatro outros atratores: brigar; brincar; desconfiar e cuidar/receber cuidado; concentração e livro.

Pelo canal da Ancestralidade comunicam os confetos de "alteração espiritual" e "violência interna". Para concluir, os alunos e alunas são caçadores desconfiados, que procuram a fartura ao seguirem a lei do seu prazer. Eles são sedutores e fecundos, assegurando-se em territórios adultos de referência (principalmente, a casa onde encontram saberes básicos, e a escola).

Tudo isso é o resultado de um processo de pesquisa cujos detalhes os atores-crianças entendem, já que tudo foi discutido no grupo-pesquisador (foi uma pesquisa de vários meses! - Fomos hóspedes da Escola durante três anos e membros da Associação comunitária).

\section{A sociopoética, um filosofar novo: criando personagens conceituais}

Lembremos como Deleuze e Guattari definem esses personagens, que pensam em nós e têm por papel manifestar os territórios, desterritorializações e reterritorializações absolutas do pensamento (Deleuze e Guattari, 1991, p. 62 (trad. minha):

O personagem conceitual não é o representante do filósofo, é até, o contrário: o filósofo é somente o envelope do seu principal personagem conceitual e de todos os outros, que são os intercessores, os verdadeiros sujeitos da sua filosofia. Os personagens conceituais são os “heterônimos” do filósofo, e o nome do filósofo, o mero pseudônimo dos seus personagens. Não sou mais eu, e sim uma aptidão do pensamento a se ver e desenvolver através de um plano que me atravessa em vários lugares. O personagem conceitual nada tem a ver com uma personificação abstrata, um símbolo ou uma alegoria, pois ele está vivendo, ele está insistindo.

Entre o plano de imanência - o caos pré-filosófico onde as problematizações filosóficas da vida têm sua origem - e o plano de consistência onde os conceitos são criados, os personagens conceptuais insistem, vivem intensamente, traçam o plano e criam os conceitos. Eles possuem traços a) páticos (características passionais, como o Idiota em Descartes, aquele que 
apaixonadamente quer pensar por si mesmo); b) relacionais (entre vários tipos humanos, conforme, por exemplo, o Amigo dos gregos); c) dinâmicos (da mesma maneira que os corpos pulam, em Kierkegaard, dançam em Nietzsche ou ainda, escorregam em filósofos pósmodernos); d) jurídicos (como contínuo protesto do pensamento contra as tentativas de submissão pelos biopoderes); e) existenciais (como modos de existência e possibilidades originais da vida, biopolíticas inventadas pela filosofia).

Ao pesquisar a noção de saúde com grupos-pesquisadores indígenas pataxó no Extreme-Sul da Bahia (com financiamento da FAPESB), esperava encontrar o personagem do Sobrevivente. De fato, encontrei dois personagens, em dois grupos-pesquisadores diferentes:

- O Marginalizado em busca de terra, do básico, da autonomia e do mundo de fora, com os seguintes traços: a) seguro no saber e trabalhador, mas com falta de firmeza na prática cotidiana por causa do conflito cultural com as práticas brancas; b) incluído na convivência comunitária onde os saberes se completam, com busca de troca autêntica com os saberes do branco; c) energizado pela Natureza, com muitos projetos e pouca base para expressar essa energia; d) na luta pela demarcação da sua terra e contra a burocracia da saúde branca; e) entre dois mundos, com risco de perder suas referências (mas sem querer adotar as do branco), o que pode enfraquecê-lo no dia-a-dia. Ele cria o confeto de saúde como terra para morar-natureza com as folhas que curam-trabalho (ter máquinas para o artesanato, barcos para pescar)-caça-arteeducação-corpo saudável.

\section{- O Demarcador de Terra-mãe com saúde e educação baseadas nos saberes dos Encantados}

com os seguintes traços: a) forte de espírito, lutador e conscientizador; b) em processo de transformação de si a partir do resgate da vida comunitária, da luta solidária e do ritual que dá força espiritual; c)atravessado pela energia dos ancestrais, que vem da terra e circula de geração em geração; d) na luta pela conquista de sua terra e pelo resgate de sua cultura, educação e saúde; e) ele se encontra (e encontra o grupo e o outro) no ritual sagrado Awê de "Amor, União e Paz”, que traz saúde, cultura, educação e saber, contra o preconceito daqueles que o assimilam à bruxaria. Ele cria o confeto de saúde como amor-união-paz.

Assim é o confeto um ritornelo, como quando povos indígenas nordestinos dançam suas danças 
rituais sagradas Toré, Torém, Porancim ou Awê, quando um filho ou filha de santo recebe seu orixá ou quando um/a capoeirista entra na roda (e, com outras referências culturais, nas performances do hip-hop): nesses três casos tradicionais brasileiros está se apresentando o evento incorporal do surgimento de fluxos espirituais, de intensidades oriundas da ancestralidade indígena ou afro-brasileira (roda dos passados que se conservam - diz Deleuze, 2002).

\section{Acontecer, tecer-juntos, eventar, fazer-vento juntos em grupos-pesquisadores sociopoéticos}

Deleuze e Guattari escrevam, na página 26 de O que é filosofia? “O conceito diz o evento, não a essência ou a coisa”. O evento é o que acontece no pensamento. É um encontro inesperado, intenso, entre traços e tensões, imediatamente coloridos por uma intensidade singular. Um devir. Os sociopoetas não pretendem criar grandes filosofias, e sim, mais humildemente, elaborar em cada pesquisa alguns confetos originais que ecoem uns em outros.

A multiplicação das técnicas de pesquisa participa da geração das variações do confeto.

A sociopoética é muito exigente quando se dá a tarefa de criar confetos, composições, misturas entre conceitos e afetos que, entre si, fazem rizoma. Mas como fazer de outro jeito? Pois no grupo-pesquisador experimentamos in vivo o equivalente do que Deleuze e Guattari dizem da arte do romanceiro: não se escreve com lembranças da infância, mas por blocos de infância que são os devires-criança do presente. Qual a intensidade-criança, fera, molécula, imperceptível, qual a intensidade-mulher, negro, índio que o grupo-pesquisador está vivenciando, na sua criação confetual? É claro que tocamos aqui uma nova dimensão da escuta sensível, que acontece para com os afetos que nascem dentro dos conceitos criados pelo grupo-pesquisador. Deleuze-Guattari citando, quase budistamente, Cézanne (1992, p. 160): ““Um minuto do mundo está passando', não se poderá conservá-la sem ‘tornar-se ela mesma’”. O grupo-pesquisador vivencia intensidades que nos tornam moléculas, com devires imprevisíveis. Daí, nossa paixão: desprender-se de si, ou seja, pensar.

\section{Referências bibliográficas}

BARBIER, René. “A escuta sensível em educação”. Cadernos ANPEd. N. 5. Belo Horizonte: ANPEd, 1993. 
BATISTA, Ma. Geovanda. Nos rizomas da alegria vamos todos Hãmiya : as múltiplas relações entre o brincar, o corpo e o território implicados no imaginário sociocultural Pataxó. Dissertação de Mestrado. UQAC/UNEB, Chicoutimi/Salvador, 2003.

BOAL, Augusto. O teatro do oprimido e outras poéticas políticas. $5^{\text {a }}$ ed. Rio de Janeiro: Civilização Brasileira, 1988.

DELEUZE, Gilles. Logique du sens. Paris: Minuit, 1969. . Le temps non chronologique. CD - Le bruit du temps. In. Rev. Chimères. N.40. Paris, Out/2002.

DELEUZE, Gilles e GUATTARI, Félix. Qu'est-ce que la philosophie ? Paris: Minuit, 1991. O que é filosofia? Rio de Janeiro: Ed. 34, 1992.

ENTRELUGARES. Revista eletrônica www.entrelugares.ufc.br - site disponível.

GAUTHIER, Jacques. “O que é pesquisar - entre Deleuze-Guattari e o candomblé, pensando mito, ciência, arte e culturas de resistência”. Rev. Educação e Sociedade. V. 20, N. 69 Campinas: CEDES/Dez.99.

- “Maquinando o saber escolar/comunitário - pesquisa sociopoética de autoria coletiva”. Panorama Acadêmico 4/5. Revista do Campus de Jacobina da UNEB, Universidade do Estado da Bahia. Jun/2000.

GAUTHIER, Jacques e GAUTHIER Leliana. «Le rapport au savoir comparé d'élèves, de parents et d'enseignants d'écoles de périphérie à Salvador de Bahia (Brésil) - étude sociopoétique». In. CHARLOT, Bernard. Les jeunes et le savoir. Perspectives internationales. Paris: Anthropos/Economica, 2001. 
GLEASON, Judith. Oyá - um louvor à deusa africana. Rio de Janeiro: Bertrand Brasil, 1999.

LEVI-STRAUSS, Claude (coord.). L’identité. Paris: PUF, 1983.

LISPECTOR, Clarice. A paixão segundo G.H. Rio de Janeiro: Rocco, 1998.

OLIVEIRA, David Eduardo de. Cosmovisão africana no Brasil. Elementos para uma filosofia afrodescendente. Fortaleza: LCR, 2003.

Filosofia da ancestralidade - corpo e mito na filosofia da educação brasileira. Curitiba:

Editora Gráfica Popular, 2007.

SANTOS, Iraci dos; GAUTHIER, Jacques; FIGUEIREDO, Nébia; PETIT, Sandra. (orgs.)

Prática da pesquisa nas ciências humanas e sociais: abordagem sociopoética. São Paulo:

Atheneu, 2005. 